\title{
Psychocultural Approach in Psychological Support
}

\section{Augustin Mubiayi Mamba*}

Professor, University of Kinshasa, Democratic Republic of the Congo

*Corresponding Author: Augustin Mubiayi Mamba, Professor, University of

Kinshasa, Democratic Republic of the Congo.

DOI: $10.31080 /$ ASPE.2020.03.0220
Received: January 31, 2020;

Published: February 10, 2020

(C) All rights are reserved by Augustin

Mubiayi Mamba.

\section{Abstract}

A scientific approach should find its relevance in its clarity and effectiveness in solving a problem. The evolution of science pushes researchers to innovate or renovate taking into account the new paradigms of the moment in order to facilitate the task of practitioners or professionals in their missions. Clinical psychology or psychotherapy cannot be the same, it should keep pace with the evolution of science. From Freud's psychoanalysis to contemporary psychotherapy, the same prejudices persist and practitioners are misunderstood to this day. Our experience in clinical practice has led us to develop an approach that allows us to think differently about our therapies, whether medical or psychological. We tell ourselves that a global approach that associates multiple dimensions of our clients' or patients' lives would provide us with precise knowledge of our practices and appreciable results. The trilogy that triangulates the psyche, the soma and the society-environment is a basic model for understanding the forces at work in behavioral and health behavior. We have applied this basic trilogy to the trilogy of mother, child and society/environment in the field of gynecological-obstetrics to improve maternal health in childbirth and in pediatrics to highlight the important role played by the mother, the family, society, the environment, in short the culture in the development and behavior of the newborn that characterizes this approach that we call the psychocultural approach. This approach is based on the idea that the behavior of a human being is strongly influenced by its culture, which comes from its community with its customs, beliefs, prejudices, ecosystem and all its environment from everywhere it has passed through in its evolution. Good health or equilibrium is found or maintained as long as there is harmony between the peaks of the trilogy, otherwise there is displeasure and illness.

Keywords: Triangulation; Harmony; Psyche; Soma; Mother; Child; Society-Environment; Culture

\section{Introduction}

The Larousse illustré (2009) defines approach as a way of approaching a subject or a movement towards something. This leads us to evoke a scientific approach or a scientific method that can be designated as the set of canons guiding or having to guide the process of production of scientific knowledge, whether it is about observations, experiments, reasoning, or theoretical calculations (wikipedia.org). It follows that "Approach" refers either to a general methodology (how to conduct research), or to a more global paradigm which consists in sharing the same methodology for common objectives and theoretical elements. It includes a set of useful and proven methods for studying a set of phenomena.

We believe that an approach is therefore a methodical process guiding a strategy for treating or solving a given problem or question. This process, which in therapy is known as a therapeutic scheme or research approach, is designed to shed intelligible and unequivocal light on how the researcher or manipulator proceeds in order to achieve his or her goals or an expected result.

There are several scientific approaches in our field of psychotherapy. However, our research on the psychological accompaniment of women in complicated childbirth situations (2018), led us to build a protocol based on a triangulation between the Mother, the Fetus and the Society. And the bases of this approach are the taking into account of multidisciplinarity in the psychological accompaniment and the framework of psychocultural influences and interactions. This study on the accompaniment of women in situations of complicated childbirth remains the basis for the application of this approach in gynaecological-obstetrics which we will discuss later as well as its extrapolation to paediatrics.

\section{Notion}

The psycho-cultural approach, as we have just underlined in the introduction, involves the triangulation of the psyche, the soma and 
the society/environment. In our pamphlet on soul healing (2003), we say that the complete and concrete man is composed of the body (outer man), the soul (inner man) and the spirit (core). But this man, in order to be realized, must evolve in a space that we call society-environment. Aristotle, quoted by Marcel Prelot [1], speaks of man as a social animal, to underline this need to belong that is in him. This leads us to affirm that man does not live in a closed vase, but rather in a network of socio-cultural interactions that influence his behaviour.

This psyche-soma-society/environment triangulation places the human organism in a situation of well-being when it is in harmony with this trilogy, when this harmony is broken in any way, the balance is tainted and both mental and physical health is thus threatened.

The psycho-cultural notion therefore implies the awareness of the career of the globality of the contour of the complete and concrete human being whose behaviour is largely influenced by society, which includes habits and customs, models, and beliefs that have contributed to the construction of his personality. This vision of things leads us to integrate the intercultural dimension. Laurent Licata and Audrey Heine (2012) conclude their introduction with "Why be interested in intercultural psychology?" by saying that intercultural psychology is a scientific discipline whose object of study lies at the intersection of culture and psychology; a branch of psychology whose explicit objective is to take into account the influence of culture on human behaviour. In this she questions the implicit universalists of psychology, while stressing that crosscultural psychologists are aware of the risks involved in focusing exclusively on cultural influences. They try to develop a nuanced and non-reductive knowledge of human psychology in relation to the cultural context.

This psychocultural approach becomes predominant in psychological care or support because culture characterizes the social group, and therefore society as a whole, and psychology is specific to the individual, to the personality. This is the essence of the conception of this triangular model.

\section{Basic trilogy}

The basic trilogy places the society-environment at the top of our conception because the human finds its meaning in this paradigm. It is the foundation of all interaction and the field of behavioural exploration. If the experimental method proceeds by the experimental design to manipulate variables, based on the principle of cause and effect, the behavioralist approach see the behaviourist approach looks for what influences the human organism to give an answer. The dynamic psychology which proceeds from psychoanalysis enters more in the personal evolutionary history of the individual since his conception with all the incessant transformations and tries to discover the psychic forces and their determinants. It is here that culture plays a major role in behavior.
The psyche embodies the soul and the spirit, which is the seat of the psychic apparatus and the libido that Freud [2] talks about in psychoanalysis. This psyche stores all memories, overflows man's past and present and thus dictates conscious and unconscious conduct through impulses. The psyche is like a motor of the body (soma); for this reason it is also called the breath of life.

The soma is the physical body, the organism that incarnates the "I" and is influenced by the psychic apparatus that is the psyche and the society-environment. In disharmony with the psyche and the society-environment the soma falls into the trap of psychosomatic and or somatopsychic illness and becomes a problem for society. The body manifests or reflects what it experiences from the psyche and culture through the society-environment. This is why good therapy cannot be considered without taking this trilogy into account.

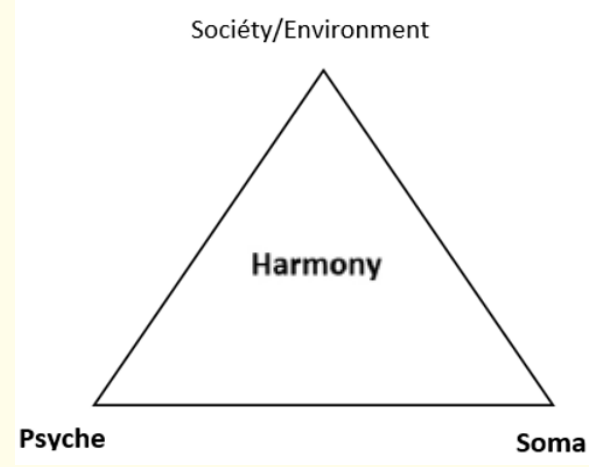

Figure 1

\section{Principle}

This basic trilogy better explains the principle of pleasure and displeasure that Freud talks about in psychoanalysis. In other words, it is about pleasure as long as there is harmony and displeasure in case of disharmony.

It is a global approach, therefore syncretic, which goes beyond the simple observatory clinic or the mere medical diagnosis, but rather the search for harmony that would be broken somewhere and do the triangulation in order to re-establish the pleasure, the relief.

Application of the approach

Application of the psychocultural approach in gynaecologicalobstetrics

As mentioned above, this psycho-cultural approach stems from our doctoral research conducted from 2015 to 2018, which consisted in constructing a protocol for the psychological support of complicated deliveries. This thesis allowed us to apply clinical psychology in gynaecological-obstetrics, in order to show the place that this practice occupies in this branch of modern medicine. 
This study is conducted in order to respond to the challenges of improving maternal health in childbirth, a subject of concern to both national and international actors seeking strategies to minimize the mortality rate of pregnant women during childbirth. It consists in enriching the medical techniques in vogue with a particular emphasis on the helping relationship (clinician-parturient in complicated childbirth situations) and the understanding of the psychosocial problems that affect the smooth running of the childbirth process in the parturient.

It is bold for a clinical psychologist to conduct a study such as this one in a field within the competence of gynaecologic-obstetricians and midwives. Indeed, our scientific curiosity would have been uncomfortable, especially with our status as clinical psychologist, if it had been based on the ambition to reverse roles. However, this is not the case in this study. On the contrary, by placing ourselves in a global and dynamic approach, we considered the problem of childbirth as a knot containing several facets, which facets could be treated in synergy between several specialties. It is this holistic view of the problem that, among other things, led us to believe that the pregnant woman lives her pregnancy not in a social and cultural vacuum, but rather in a network of social and cultural relations. Thus, society takes an interest in her while awaiting the arrival of the newborn, who in terms of potential will in the future occupy status and play roles in the society in question. Hence the use of the conceptual model that we have described as the Society - Mother - Child (S M E) trilogy where the relationships between the three agents involved in the problem of childbirth are more reciprocal than univocal.

It should be noted that conducting a study that articulates concepts related to psychology, culture, anatomy, medicine, even development economics, etc., requires a real effort of conceptualization. And the establishment of a conceptual apparatus in this work was the result of the holistic vision that we had to have as clinical psychologists, both in terms of conception and understanding of the problem of complicated childbirth and its outcome.

This brings us to the complications related to pregnancy and childbirth, and therefore to the issue of high-risk or pathological pregnancy and childbirth. And the most frequent complications are eclampsia, also called gestational toxaemia, gestational diabetes or the threat of premature delivery.

It is well accepted that pregnancy is a physiological state and not a pathology in itself, but as the complications that it can entail are such as to lead the woman and even her future child to the risk of death, its management requires a synergy of care involving the medical, psychological, cultural and even spiritual dimension.

The inspiration of the Luba-Kasaï therapeutic practices has revealed several factors that can contribute to the complication of childbirth apart from infections and other programmed factors These factors are psychological and cultural. Hence the idea of designing a model that better responds to the resolution of this problem in order to improve maternal health in childbirth (2018).

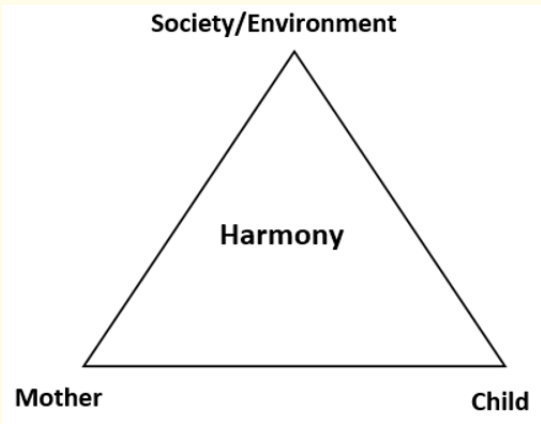

Figure 2

Application of the psycho-cultural approach in paediatrics

Having conceived the mother-child society trilogy, we will border the issue of pediatric and neonatal care, which consists of talking about the health or well-being of the newborn. This issue involves many aspects of the development and behaviour of that baby. Lissaner and Clayden (2014) point out that a child's health is profoundly influenced by his or her social, cultural and physical environment.

According to Bronfenrenner (1979), the child's universe is made up of extensive and interconnected socio-environmental layers that overlap and influence his or her health and development.

As a result, it can be said that both the physical and emotional development of the infant is both species-specific and entirely related to relationships with different partners.

In thinking about this, account should be taken of the child, the child's family and their immediate social environment, the local social fabric, as well as the national and international environment. Hence, our ability to intervene as a clinician must be seen in the context of interdependent influences on health.

This approach is the basis of our psychocultural approach, which calls for multidisciplinary management of the newborn, taking into account this framework of psychocultural influences and interactions. Hence, our mother-child, society/environment trilogy. An approach that considers the child as a being who must evolve, not in a closed vase, but rather in a socio-cultural network such that the harmony that exists there promotes the child's behavioural and developmental balance among others. This is the meaning of the above trilogy (Figure 2) 
This trilogy allows us to understand the key factors in the development and behaviour of the newborn.

This means that one cannot conceive of paediatrics without reference to the mother, the birth, and conception first. Then to the society or environment in which the newborn has a role to play.

The apex of this approach is the society or environment, material and immaterial, physical and psychic. We study the immediate family, the extended family, the school, the village, the country, the customs, the education of the parents, the ecosystem, the recurring events in the life of the society. In short, all those that bring a child into society.

This is the first level of influence in a child's development and behaviour. What some call "the child in society to the environment". This environment acts continuously on the child's life as Sigmund Freud's unconscious.

In the Luba culture, as in many African cultures, the arrival of a newborn child is a great event. A Luba expression says "Kulela nkuabanya mesu" which translates as "to give birth is to propagate one's vision" [5]. For her part, Kamanga Mbuyi [6] says that "childbirth is a major event in family life; like a funeral, childbirth is an occasion for the expression of alliance relations as well as the tensions existing between spouses and the lineages that find themselves allied through their intermediaries. It is the covenant and the continuity of the chain of filiation that underpin social life. The high value that society places on the child is the basis of the special privilege and treatment accorded to the pregnant woman who is to become a mother.

The child represents continuity, power and offspring. A Luba anecdote says: "Kabondo Ka muana wa dipanda, Bakulele walela biebe" which means "a palm tree begets a palm tree, child as you were also born" [5]. The newborn is, like the mother's ego, caught between the mother's influence and that of society, and this largely determines its growth and behaviour.

The mother, the mother-to-be, the birthing agent. She is the first to be questioned when the newborn presents discomfort.

This notion also includes the father, but since it is the mother who carries the pregnancy, she bears the brunt of the actual weight of the birth and her influence is much more direct in the child than the father's influence.

By referring to the mother in paediatric and neo-natal care, we want to show the psycho-affective factors which, in one way or another, facilitate harmonious emotional development. These include emotional deficiency, somatic expressive disorders, infant depression, etc. We believe that we encourage mother-child fantasy and emotional interactions in addition to bodily and behavioural interactions.
John Bowlby, quoted by Jeremy Holmes [7], speaking of attachment, points out that the propensity to form strong bonds with particular individuals exists from birth and is maintained throughout life. These include crying, sucking, grasping, etc., which maintain physical closeness and accessibility to the preferred attachment figure that is often represented by the mother. This is what Bowlby calls early mother/child bonding in human development $[8,9]$.

\section{Conclusion}

Developing an approach that is consistent with psychotherapy has been an interesting exercise for us, especially since it involves producing and providing a working tool for our researchers and practitioners in the field. This approach is part of a global and syncretic framework and opens the way to several dimensions in the care of patients, whether medical or psychological. It involves multidisciplinary input where cultural anthologists, sociologists, psychologists and physicians each have a contribution to make.

\section{Bibliography}

1. Marcel Prélot. Politique d'Aristote, Presse universitaire de France, Paris (1950).

2. FREUD S. Psychoanalysis and theory of libido, in Euvres complètes, XVI, translated under the dir. of J. LAPLANCHE, Paris, PUF (1923).

3. Lissauer T and Clayden G. Pédiatrie Manuel illustré 4eme Ed de Boeck Supérieur (2014).

4. Bronfenbrenner U. "Context of Child Rearing-problems and Prospects”. American Psychologist 34 (1979): 844-850.

5. Mubiayi Mamba A. Description des conséquences de violations des coutumes luba-Kasaï et leurs thérapies, Mémoire DES, UNIKIN, University of Kinshasa (2015).

6. Kamanga Mbuyi T. Rite de réparation d'inceste et son symbolisme chez les Baluba du Kasaï. Contribution à l'ethno-thérapie, PhD thesis UNIKIN. University of Kinshasa (2001).

7. Holmes J and John Bowlby. Attachment Theory. Taylor and Francis. New Edition. London (2014).

8. Mubiayi Mamba A. Cure of the soul or psychological cure (2013).

9. Mubiayi Mamba A. Construction d'un protocole d'accompagnement psychologique d'accouchements compliqués: essaie d'une psychothérapie inspirée des pratiques traditionnelles luba-Kasaï. PhD thesis UNIKIN, University of Kinshasa (2018).

\section{Assets from publication with us}

- Prompt Acknowledgement after receiving the article

- Thorough Double blinded peer review

- Rapid Publication

- Issue of Publication Certificate

- High visibility of your Published work

Website: www.actascientific.com/

Submit Article: www.actascientific.com/submission.php

Email us: editor@actascientific.com

Contact us: +919182824667 